\title{
The role of stereotactic radiosurgery in the multimodal management of growth hormone-secreting pituitary adenomas
}

\author{
Christopher J. Stapleton, B.S., ${ }^{1,2}$ Charles Y. Liu, M.D., Ph.D., ${ }^{1,3}$ \\ and Martin H. Weiss, M.D. ${ }^{1}$ \\ ${ }^{1}$ Department of Neurological Surgery, Keck School of Medicine, University of Southern California, Los \\ Angeles, California; ${ }^{2}$ Harvard-M.I.T. Division of Health Sciences and Technology, Harvard Medical School, \\ Boston, Massachusetts; and ${ }^{3}$ Division of Chemistry and Chemical Engineering, California Institute of \\ Technology, Pasadena, California
}

\begin{abstract}
Growth hormone (GH)-secreting pituitary adenomas represent a common source of GH excess in patients with acromegaly. Whereas surgical extirpation of the culprit lesion is considered first-line treatment, as many as $19 \%$ of patients develop recurrent symptoms due to regrowth of previously resected adenomatous tissue or to continued growth of the surgically inaccessible tumor. Although medical therapies that suppress GH production can be effective in the management of primary and recurrent acromegaly, these therapies are not curative, and lifelong treatment is required for hormonal control. Stereotactic radiosurgery has emerged as an effective adjunctive treatment modality, and is an appealing alternative to conventional fractionated radiation therapy. The authors reviewed the growing body of literature concerning the role of radiosurgical procedures in the treatment armamentarium of acromegaly, and identified more than 1350 patients across 45 case series. In this review, the authors report that radiosurgery offers true hormonal normalization in $17 \%$ to $82 \%$ of patients and tumor growth control in $37 \%$ to $100 \%$ of cases across all series, while minimizing adverse complications. As a result, stereotactic radiosurgery represents a safe and effective treatment option in the multimodal management of primary or recurrent acromegaly secondary to GH-secreting pituitary adenomas. (DOI: 10.3171/2010.7.FOCUS10159)
\end{abstract}

$\begin{array}{llllll}\text { KEY WORDS } & \text { acromegaly } & \bullet & \text { growth hormone } & \bullet & \text { insulin-like growth factor-I } \\ \text { pituitary adenoma } & \bullet & \text { radiosurgery }\end{array}$

$\mathrm{A}$ CROMEGALY consists of a constellation of clinical signs and symptoms caused by an excess production of GH. The onset of this disease can be quite insidious, and common clinical manifestations include acral overgrowth, soft tissue hypertrophy, metabolic derangements, and cardiovascular complications. ${ }^{37}$ While a host of pathological entities can cause $\mathrm{GH}$ overproduction, more than $90 \%$ of patients with acromegaly harbor a GH-secreting pituitary adenoma. ${ }^{49}$ Although these adenomas arise from the benign proliferation of somatotroph cells within the anterior pituitary gland, the pituitary's confined location within the sella turcica and close approximation to important neurovascular structures render masses in this region problematic. Therefore, aside from complications secondary to $\mathrm{GH}$ excess, patients may also

Abbreviations used in this paper: $\mathrm{GH}=$ growth hormone; GKS = Gamma Knife surgery; IGF = insulin-like growth factor; LINAC = linear accelerator; SRS = stereotactic radiosurgery. experience headache, visual loss, cranial nerve deficits, and symptoms of additional pituitary hormone dysregulation. ${ }^{18}$

Surgical extirpation of the culprit lesion is considered first-line treatment and has the distinct advantage of instantaneously lowering GH levels by directly removing the source of hormone production. ${ }^{28}$ Recent studies estimate postoperative endocrinological remission rates to be $68 \%$ to $95 \%$, irrespective of tumor volume. ${ }^{28,34} \mathrm{De}$ spite this clinical efficacy, not only is surgery alone not curative in a select cohort of patients, but recurrent acromegaly following initial postoperative hormonal remission is reported to occur in as many as $19 \%$ of cases. ${ }^{28} \mathrm{Al}-$ though regrowth of previously resected tumor has been documented, ${ }^{16}$ these recurrences most likely represent continued growth of nonresectable tumor tissue, either due to parasellar invasion or involvement of neighboring neurovascular structures. ${ }^{18,31,37}$ Stereotactic radiosurgery has emerged as a noninvasive adjuvant treatment modal- 


\section{J. Stapleton, C. Y. Liu, and M. H. Weiss}

ity for such recurrent or surgically inaccessible lesions. Unlike conventional fractionated radiotherapy, SRS delivers focused radiation to a precisely defined target in a single session and minimizes radiation exposure to adjacent normal structures. ${ }^{3,29,50}$ Over the past two decades, numerous case series have described the efficacy of SRS in patients harboring GH-secreting pituitary adenomas. In this report, we review the results from this robust body of literature, and highlight postradiosurgical rates of endocrinological remission and tumor growth control as well as assess the potential advantages and limitations of SRS in the multimodal management of acromegaly.

\section{Methods}

\section{Data Acquisition}

A PubMed search (National Library of Medicine) was performed to identify all articles pertaining to the use of SRS for the treatment of acromegaly. Surgical series describing endocrinological and radiographic outcomes were analyzed in detail and reference lists were reviewed for additional articles not identified in the original PubMed search. Pertinent clinical characteristics extracted from each report include the stereotactic radiosurgical unit; marginal radiation dose; rate of pituitary suppressive medication used during SRS; tumor size and prevalence of cavernous sinus invasion; rates of endocrinological remission and tumor growth control; and SRS-associated complications. Case series utilizing GKS, LINAC-based SRS, and CyberKnife radiosurgical systems are included in our analysis. Given a variety of confounding factors, however, no effort was made to directly compare the efficacies of these methods of SRS.

\section{Radiosurgical Techniques}

Unlike conventional radiotherapy, in which patients receive a target dose of radiation to the entire brain fractionated over numerous sessions, radiosurgery aims to deliver a high dose of radiation to a precise intracranial region during a single session..$^{27}$ The ability to focus ionizing radiation on discrete brain lesions while sparing critical adjacent neurovascular structures may improve local tumor control as well as reduce the adverse effects associated with traditional radiation therapies. ${ }^{51}$ The Gamma Knife utilizes cross-firing beams from 201 cobalt-60 sources to deliver ionizing radiation (gamma rays) to an intracranial target. The most commonly used radiosurgical unit for pituitary lesions, this system allows for a high degree of 3D conformity between the radiation field and the target of interest and offers better preservation of surrounding normal structures than conventional radiotherapy. ${ }^{18,19}$ Similar to the Gamma Knife, LINACbased systems deliver beams of photon radiation in multiple arcs to a defined intracranial structure, ${ }^{50}$ and allow neurosurgeons to target lesions with a high degree of fidelity and to minimize the extent of collateral damage to surrounding neurovascular elements.

Both the Gamma Knife and traditional LINAC-based systems require the use of a stereotactic frame for rigid immobilization of the head during the radiosurgical procedure. The CyberKnife is a newly developed LINAC- based system that uses image guidance software to adjust in real-time the precise location of radiation therapy and, thus, does not require the use of a stereotactic frame. ${ }^{1}$ Irrespective of the radiosurgical unit employed, dose selection and treatment parameters vary depending on the tumor location and size, relationship of the adenoma to the optic apparatus and other eloquent structures, dose and timing of any pretreatment conventional radiotherapy, and other patient-specific characteristics.

\section{Results}

Tables 1 and 2 summarize data obtained from case series in which stereotactic radiosurgical procedures were employed in the multimodal management of GH-secreting pituitary adenomas. Across all series, more than 1350 patients underwent SRS using either Gamma Knife- or LINAC-based systems for the treatment of primary or recurrent acromegaly. The mean duration of endocrinological and radiographic follow-up ranged from greater than 6 months to 100 months. The average tumor volume was between $0.9 \mathrm{~cm}^{3}$ and $11.3 \mathrm{~cm}^{3}$ and, where reported, $21 \%$ to $100 \%$ of patients harbored lesions that extended into the cavernous sinus. The mean marginal radiation dose employed across all series ranged from 14.3 to $34.4 \mathrm{~Gy}$. Approximately $71 \%$ of patients throughout the series had undergone transsphenoidal or transcranial neurosurgical resection of their pituitary adenoma prior to radiosurgery, while $11 \%$ had received antecedent conventional fractionated radiotherapy. Although reported in only half of the case series, approximately $75 \%$ of patients had discontinued all suppressive medications for more than 6 to 8 weeks prior to radiosurgery. While the definition of true endocrinological remission was quite variable among the series, approximately $47 \%$ of patients fulfilled the given criteria for hormonal remission, and an additional 32\% achieved endocrinological normalization after radiosurgery with adjunctive medical therapy. Compared with preradiosurgical volumes, on average more than $97 \%$ of tumors decreased or remained the same in size at the time of the latest follow-up.

\section{Endocrinological Remission and Control}

Whereas the precise criteria for characterizing endocrinological remission following SRS were inconsistent across the case series, the most widely accepted definition is a random GH level less than $2 \mathrm{ng} / \mathrm{ml}$ or a GH level less than $1 \mathrm{ng} / \mathrm{ml}$ following an oral glucose tolerance test in addition to a normal IGF-I level when controlled for age and sex. ${ }^{35}$ Importantly, these measurements are recorded while the patient is not taking pituitary suppressive medications. If the above criteria are met after radiosurgery with the aid of adjunctive medical therapy, the patient is considered to have achieved endocrinological control. ${ }^{16}$ Using the aforementioned strict criteria for hormonal remission, the range of endocrinological normalization was $17 \%$ to $82 \%$, and an additional $4 \%$ to $47 \%$ of patients achieved hormonal control following radiosurgery. 2,4,5,14,16,21,33,45-47,53,54,57,58 For instance, Pollock et al. ${ }^{45}$ observed an endocrinological remission rate of $67 \%$ and Ikeda et al.${ }^{14}$ observed normalized hormonal levels in $82 \%$ of patients following GKS. Using LINAC-based SRS, Voges et al. ${ }^{58}$ reported a true remission rate of $37.5 \%$ 


\section{Stereotactic radiosurgery for acromegaly}

TABLE 1: Summary of previously reported case series involving SRS in patients with acromegaly (Part I)*

\begin{tabular}{|c|c|c|c|c|c|c|c|}
\hline Authors \& Year & $\begin{array}{l}\text { SRS } \\
\text { Unit }\end{array}$ & $\begin{array}{l}\text { No. of } \\
\text { Patients }\end{array}$ & $\begin{array}{l}\text { Mean FU } \\
\text { (mos) }\end{array}$ & $\begin{array}{c}\text { Interventions Prior to } \\
\text { SRS (\%) }\end{array}$ & $\begin{array}{l}\text { Off Medication } \\
\text { During SRS (\%) }\end{array}$ & $\begin{array}{c}\text { Mean Marginal } \\
\text { Radiation Dose (Gy) }\end{array}$ & $\begin{array}{l}\text { Cavernous Sinus } \\
\text { Invasion }(\%)\end{array}$ \\
\hline Hayashi et al., 2010 & GK & 25 & $36 \dagger$ & surg (100) & NA & $21.8 \dagger$ & 100 \\
\hline Iwai et al., 2010 & GK & 26 & $84 \ddagger$ & surg (85) & 85 & 20.2 & 35 \\
\hline Castinetti et al., $2009^{4}$ & GK & 43 & 100 & $\operatorname{surg}(70)$ & 53 & NA & 21 \\
\hline Cho et al., 2009 & CK & 6 & 35 & surg (83) & NA & NA & NA \\
\hline Swords et al., 2009 & GK & 10 & 38.5 & CRT (100); surg (80) & 40 & NA & NA \\
\hline Wan et al., 2009 & GK & 103 & $67 \dagger$ & surg (14)† & 100 & 21.4 & NA \\
\hline Jagannathan et al., 2008 & GK & 95 & 57 & CRT (5); surg (100) & 71 & 22 & 35 \\
\hline Losa et al., 2008 & GK & 83 & $69 \ddagger$ & CRT (1); surg (100) & 76 & 25 (goal) & NA \\
\hline Pollock et al., 2008 & GK & 27 & $47 \ddagger$ & CRT (7); surg (93) & 100 & $20 \ddagger$ & NA \\
\hline Tinnel et al., 2008 & GK & 9 & $35 \ddagger$ & CRT (11); surg (75) & 56 & NA & NA \\
\hline Pollock et al., 2007 & GK & 46 & $63 \ddagger$ & CRT (13); surg (93) & 59 & $20 \ddagger$ & 85 \\
\hline Roberts et al., 2007 & CK & 9 & 25 & surg (89) & 67 & 21 & NA \\
\hline Vik-Mo et al., 2007 & GK & 61 & 66 & surg (92) & NA & 26.5 & NA \\
\hline Jezková et al., 2006 & GK & 96 & 54 & CRT (11.5); surg (74) & 100 & 32 & NA \\
\hline Voges et al., 2006 & LINAC & 64 & 54 & CRT (7)†; surg (53)† & NA & 16.5 & $89 \dagger$ \\
\hline Castinetti et al., 2005 & GK & 82 & 49.5 & CRT (2); surg (77) & 49 & 25.7 & 89 \\
\hline Kajiwara et al., 2005 & CK & 2 & $35 \dagger$ & CRT (10)†; surg (48)† & NA & $14.3 \dagger$ & NA \\
\hline Kobayashi et al., 2005 & GK & 67 & 63 & CRT (3); surg (73) & 37 & 18.9 & NA \\
\hline Attanasio et al., 2003 & GK & 30 & $46 \ddagger$ & CRT (13); surg (90) & 60 & $20 \ddagger$ & NA \\
\hline Choi et al., 2003 & GK & 9 & $42.5 \dagger$ & $\operatorname{surg}(32) \dagger$ & NA & $28.5 \dagger$ & NA \\
\hline Jane et al., 2003 & GK & 64 & $>18$ & surg (100) & 100 & $15 \dagger$ & NA \\
\hline Petrovich et al., 2003 & GK & 6 & 41 & CRT (10)†; surg (95)† & NA & $15 \dagger$ & $96 \dagger$ \\
\hline Swords et al., 2003 & LINAC & 13 & $25 \ddagger$ & CRT (100); surg (77) & 23 & 10 (mode) & $67 \dagger$ \\
\hline Feigl et al., 2002 & GK & 9 & $55 \dagger$ & surg (100) & NA & $15 \dagger$ & NA \\
\hline Pollock et al., 2002 & GK & 26 & $36 \dagger \ddagger$ & CRT (21)†; surg (86)† & 69 & $20.1 \dagger$ & $70 \dagger$ \\
\hline Ikeda et al., 2001 & GK & 17 & 56 & surg (100) & 100 & 25 & 100 \\
\hline Fukuoka et al., 2001 & GK & 9 & 42 & surg (89) & NA & 20 & 100 \\
\hline Izawa et al., 2000 & GK & 29 & $>6$ & surg (37)† & NA & $22.5 \dagger$ & 29 \\
\hline Shin et al., 2000 & GK & 6 & 43 & surg (67) & 100 & 34.4 & 100 \\
\hline Zhang et al., 2000 & GK & 68 & 34 & CRT (4); surg (14) & 100 & 31.3 & NA \\
\hline Hayashi et al., 1999 & GK & 22 & 16 & $\operatorname{surg}(49) \dagger$ & NA & 22.5 & 24 \\
\hline Inoue et al., 1999 & GK & 12 & $>24$ & surg (100) & 100 & 20.9 & 100 \\
\hline Kim et al., $1999^{23}$ & GK & 2 & $12 \dagger \ddagger$ & none & 100 & $22 \dagger$ & NA \\
\hline Kim et al., $1999^{24}$ & GK & 11 & $27 \dagger$ & surg (55) & NA & $28.7 \dagger$ & NA \\
\hline Laws \& Vance, 1999 & GK & 56 & NA & NA & NA & NA & NA \\
\hline Mokry et al., 1999 & GK & 10 & 46 & CRT (4)†; surg (96)† & NA & 16 & NA \\
\hline Landolt et al., 1998 & GK & 16 & $>17$ & CRT (44); surg (100) & 69 & 25 & NA \\
\hline Lim et al., 1998 & GK & 16 & $25.5 \dagger$ & CRT (2)†; surg (51)† & NA & $25.4 \dagger$ & $22 \dagger$ \\
\hline Martínez et al., 1998 & GK & 7 & $36 \dagger$ & surg (57) & NA & 24.7 & 57 \\
\hline Mitsumori et al., 1998 & LINAC & 1 & 47 & CRT (22)† & NA & NA & $61 \dagger$ \\
\hline Morange-Ramos et al., 1998 & GK & 15 & $20 \dagger$ & CRT (7); surg (87) & NA & 28.7 & $76 \dagger$ \\
\hline Pan et al., 1998 & GK & 16 & $29 \dagger$ & CRT (4)†; surg (16)† & NA & 28.6 & NA \\
\hline Witt et al., 1998 & GK & 20 & 32 & NA & NA & 19 & NA \\
\hline Yoon et al., 1998 & LINAC & 2 & $49 \dagger$ & surg (96)† & NA & NA & NA \\
\hline Park et al., 1996 & GK & 7 & $15 \dagger$ & surg (14) & NA & $27.1 \dagger$ & NA \\
\hline
\end{tabular}

* $\mathrm{CK}=$ CyberKnife; CRT = conventional radiotherapy; FU = follow-up; GK = Gamma Knife; NA = not available; surg = transsphenoidal or transcranial surgery.

$\dagger$ Values represent data pertaining to both somatotroph and nonsomatotroph pituitary tumors.

$\ddagger$ Median value. 
C. J. Stapleton, C. Y. Liu, and M. H. Weiss

TABLE 2: Summary of previously reported case series involving SRS in patients with acromegaly (Part II)*

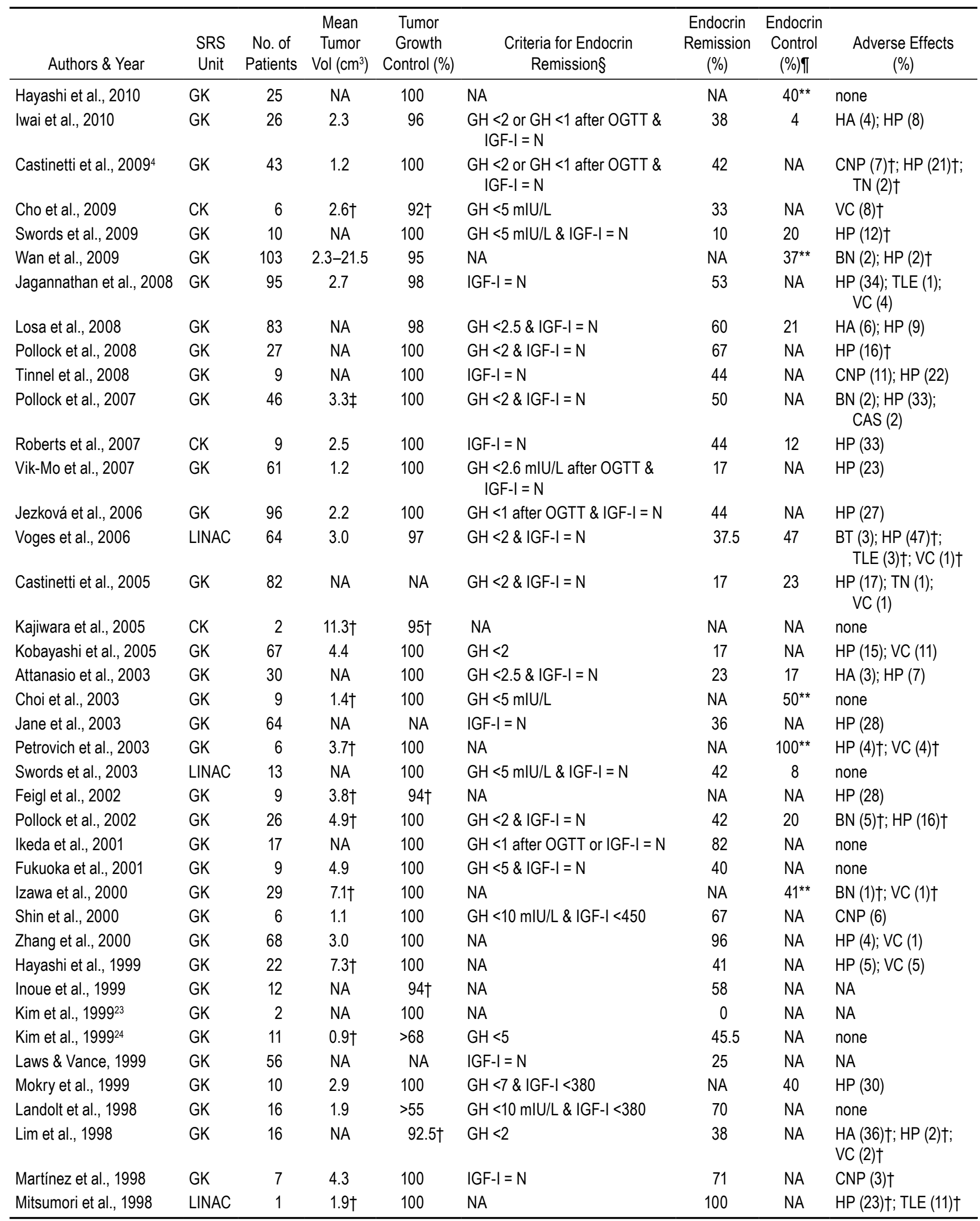

(continued) 
Stereotactic radiosurgery for acromegaly

TABLE 2: Summary of previously reported case series involving SRS in patients with acromegaly (Part II)* (continued)

\begin{tabular}{|c|c|c|c|c|c|c|c|c|}
\hline Authors \& Year & $\begin{array}{l}\text { SRS } \\
\text { Unit }\end{array}$ & $\begin{array}{l}\text { No. of } \\
\text { Patients }\end{array}$ & $\begin{array}{l}\text { Mean } \\
\text { Tumor } \\
\text { Vol }\left(\mathrm{cm}^{3}\right)\end{array}$ & $\begin{array}{c}\text { Tumor } \\
\text { Growth } \\
\text { Control (\%) }\end{array}$ & $\begin{array}{l}\text { Criteria for Endocrin } \\
\text { Remission§ }\end{array}$ & $\begin{array}{l}\text { Endocrin } \\
\text { Remission } \\
(\%)\end{array}$ & $\begin{array}{c}\text { Endocrin } \\
\text { Control } \\
(\%) \Uparrow\end{array}$ & $\begin{array}{c}\text { Adverse Effects } \\
(\%)\end{array}$ \\
\hline $\begin{array}{l}\text { Morange-Ramos et al., } \\
1998\end{array}$ & GK & 15 & 1.5 & $>37 \dagger$ & $\mathrm{GH}<5 \& \mid \mathrm{GF}-\mathrm{I}=\mathrm{N}$ & 20 & NA & HP (16)†; TN (7) \\
\hline Pan et al., 1998 & GK & 16 & 1.0 & 100 & NA & 100 & NA & none \\
\hline Witt et al., 1998 & GK & 20 & NA & 94 & $|G F-|=N$ & 20 & NA & NA \\
\hline Yoon et al., 1998 & LINAC & 2 & NA & 100 & $\mathrm{GH}<5$ & 100 & NA & HP (29) \\
\hline Park et al., 1996 & GK & 7 & NA & 100 & $\mathrm{GH}<5$ & 57 & NA & none \\
\hline
\end{tabular}

* $\mathrm{BN}=$ brain necrosis; $\mathrm{CAS}=$ carotid artery stenosis; $\mathrm{CNP}=$ cranial nerve palsy; Endocrin = Endocrinological; $\mathrm{HA}=$ headache; $\mathrm{HP}=$ hypopituitarism; $\mathrm{N}=$ normal value when controlled for age and sex; OGTT = oral glucose tolerance test; $T L E=$ temporal lobe epilepsy; $\mathrm{TN}=$ trigeminal neuralgia; $\mathrm{VC}=$ visual complications.

$\dagger$ Values represent data pertaining to both somatotroph and nonsomatotroph pituitary tumors.

$\ddagger$ Median value.

$\S \mathrm{GH}$ in $\mathrm{ng} / \mathrm{ml}$ or $\mathrm{mIU} / \mathrm{L}$ (as specified); IGF-l in $\mathrm{ng} / \mathrm{ml}$.

II Endocrinological control indicates postradiosurgical hormonal normalization with adjuvant medical therapy.

** Percentages indicate overall rates of hormonal normalization irrespective of postradiosurgical medical therapy.

and an additional endocrinological control rate of $47 \%$ in their series of 64 patients with acromegaly. When more lenient definitions were employed, the range of hormonal remission rates was 0 to $100 \%$ while rates of endocrinological control ranged from $8 \%$ to $100 \%$ at the time of the latest follow-up. . $-10,12,13,15,17,18,20,22-25,27,30,32,36,38-42,44,48,52,55,59-62_{\text {Using }}$ only a normalized IGF-I level as the criterion for hormonal remission, Jagannathan et al. ${ }^{18}$ reported an endocrinological normalization rate of 53\% at a mean follow-up time of 57 months. Zhang et al. ${ }^{62}$ observed biochemical remission in $96 \%$ of their 68 patients, although the criteria for remission are not given. Not all series, however, documented such impressive rates of endocrinological remission at the time of last follow-up. As examples, Kobayashi et al. ${ }^{25}$ and Castinetti et al. ${ }^{5}$ observed hormonal normalization in only $17 \%$ of patients when they were not receiving medical therapy. Such disparities likely reflect important differences in patient populations, adenoma characteristics, preradiosurgical hormonal control, and treatment regimens.

Although disagreement existed across the case series, several studies identified factors that independently predicted postradiosurgical endocrinological outcomes. Choi et al. ${ }^{8}$ found that a greater maximum radiation dose was associated with a higher rate of hormonal remission. Kim et al. ${ }^{24}$ reported a similar finding, and also discovered that patients with larger tumor volumes were more likely to achieve biochemical remission than those with smaller masses. Interestingly, while the maximum radiation dose significantly predicted hormonal remission in these studies, Kim et al., ${ }^{24}$ Losa et al., ${ }^{33}$ Pollock et al., ${ }^{47}$ and Zhang et al. ${ }^{62}$ found that the marginal radiation dose was not a significant prognostic factor. In addition, in the studies of Castinetti et al. ${ }^{5}$ and Jezková et al., ${ }^{21}$ preradiosurgical GH and IGF-I levels were found to predict posttreatment outcomes. Not surprisingly, those patients with near-normal GH or IGF-I levels were more likely to achieve hormonal remission than patients with markedly abnormal baseline values. However, Landolt et al. ${ }^{26}$ and Pollock et al., ${ }^{46,47}$ identified arguably the most meaning- ful prognostic indicator of postradiosurgical hormonal remission. In both series, the concomitant use of pituitary suppressive medications during radiosurgery was shown to reduce the overall rate of and increase the time to hormonal remission. Finally, despite a mean tumor growth control rate of $97 \%$ across all series, no study identified a significant correlation between change in adenoma size and eventual hormonal normalization.

Although the mean time to hormonal remission following adjuvant radiosurgery was not consistently reported across the case series in our analysis, several studies did record actuarial rates of endocrinological normalization. In the study by Jezková et al., ${ }^{21}$ while only $15 \%$ of patients achieved hormonal normalization 12 months after SRS, $29 \%, 44 \%$, and $57 \%$ of patients were found to be in remission at 36, 60, and 96 months, respectively. Moreover, Vik-Mo et al. ${ }^{57}$ reported normal IGF-I levels in $45 \%, 58 \%$, and $86 \%$ of patients at 36,60 , and 120 months following radiosurgery, respectively. Finally, although Jagannathan et al. ${ }^{18}$ observed an absolute remission rate of $53 \%$ with a mean time to remission of 30 months, a more detailed analysis of the data indicates that $29 \%, 42 \%$, and $53 \%$ of patients achieved normalized IGF-I levels at 24,48 , and greater than 85 months after radiosurgery, respectively.

\section{Tumor Growth Control}

The rate of tumor growth control, defined as reduction or stabilization of tumor volume, ranged from more than $37 \%$ to $100 \%$ across all series, with an average rate of control of $97 \%$. Jagannathan et al. ${ }^{18}$ reported that $92 \%$ of patients with adequate radiographic follow-up demonstrated a decrease in tumor size following GKS and that an additional $6 \%$ showed no change in tumor volume. Voges et al. ${ }^{58}$ treated 64 patients with acromegaly with LINAC-based SRS and reported that $23 \%$ experienced a reduction in tumor volume while $73 \%$ had tumors that did not change significantly in size. To date, the largest series evaluating the use of the CyberKnife in the treatment armamentarium of acromegaly is by Roberts et al. ${ }^{48}$ 
In this study, 9 patients received CyberKnife SRS and none demonstrated tumor enlargement at the time of last follow-up. Despite these impressive statistics, the rate of tumor growth control did not correlate with rates of endocrinological remission. ${ }^{2,16,21,57}$

\section{Adverse Effects}

The overall rate of serious complications following radiosurgery was quite low across all series. New-onset anterior pituitary hormone deficiency was the most common adverse effect, and was noted in 0 to $47 \%$ of cases. ${ }^{2,4,5,9,13,16,18,20,21,25,32,33,38-40,44-48,54,55,57-59,61,62}$ Feigl et al. ${ }^{9}$ reported a $28 \%$ incidence of hypopituitarism following radiosurgery, and noted that the degree of hormonal dysfunction was related to the radiation dose received by the pituitary stalk. However, the true incidence of SRS-induced hypopituitarism is difficult to assess accurately, as many patients have undergone prior resection or conventional fractionated radiation therapy, both of which independently increase the likelihood of developing anterior pituitary hormone dysfunction. For instance, in the study by Jagannathan et al., ${ }^{18}$ of the 4 patients who developed visual complications, 3 had received prior fractionated radiation therapy.

Despite the proximity of the optic apparatus to the pituitary gland, only 10 case series ${ }^{5,713,17,18,25,32,44,58,62}$ in our analysis reported postradiosurgical visual complications, with Kobayashi et al. ${ }^{25}$ demonstrating the highest incidence at $11 \%$. The low rate of visual complications following SRS likely stems from each group's attempt to limit the dose received by the optic apparatus to 8-10 Gy. Moreover, Tinnel et al. ${ }^{55}$ reported new-onset cranial nerve palsies in $11 \%$ of patients, although cranial neuropathies were only observed in 3 other studies.,36,52 Headache, trigeminal neuralgia, temporal lobe epilepsy, brain necrosis, and carotid artery stenosis were other documented complications of SRS, although these were noted relatively infrequently across all series. Although none of the case studies were adequately powered to identify parameters that predict postradiosurgical complication rates, several groups did note that adverse effects were more commonly observed in patients who had received prior fractionated radiation therapy. ${ }^{18,47}$

\section{Discussion}

Without proper control of systemic growth levels, patients with acromegaly will follow a course of insidious yet progressive decline. The use of pituitary suppressive medications, such as somatostatin agonists or $\mathrm{GH}$ receptor antagonists, may minimize some of the metabolic sequelae of GH excess, but many patients are either only partially controlled with these therapies or become resistant after extended treatment periods ${ }^{37}$ In addition, medical therapy is not curative and, therefore, lifelong treatment is required for adequate hormonal control. Current estimates demonstrate that $75 \%$ to $90 \%$ of patients with GH overproduction harbor a GH-secreting pituitary adenoma, and surgical removal remains the first-line treatment modality ${ }^{49}$ Not only does resection remove the source of GH excess, but it also relieves any compression or mass effect the tumor may be exerting on surrounding neurovascular structures. ${ }^{28}$ Surgi- cal extirpation is effective in inducing hormonal remission in more than $68 \%$ to $95 \%$ of patients with GH-secreting adenomas, yet a select cohort of patients develop recurrent acromegaly due either to regrowth of previously resected adenomatous tissue or to continued growth of surgically inaccessible tumor. ${ }^{28,34}$ Prior to the development and modernization of current radiosurgical systems, fractionated radiation therapy was used in the treatment algorithm for patients with acromegaly refractory to medical and surgical interventions. Although early reports document endocrinological remission following radiotherapy in more than $60 \%$ of cases, these studies frequently employed definitions of remission that were more forgiving than current standards. ${ }^{27}$ Mitsumori et al. ${ }^{38}$ compared the efficacy of SRS and fractionated radiotherapy in the adjuvant treatment of hormone-secreting pituitary adenomas, and discovered that the overall incidence of endocrinological normalization was roughly equal between the 2 treatment modalities. However, patients who received SRS achieved remission in 8.5 months, whereas those in whom fractionated radiotherapy was administered did not reach hormonal normalization for 18 months. Similarly, Landolt et al. ${ }^{27}$ directly compared GKS to traditional fractionated radiation therapy and found that the percentage of hormonal normalization was roughly similar between the 2 groups, but that the time to remission was much shorter in the radiosurgical group (17 months vs 85 months, respectively). In addition to a more rapid normalization of hormone levels, SRS is also associated with a lower rate and narrower spectrum of adverse effects than conventional radiotherapy. In the study by Landolt et al., ${ }^{27} 16 \%$ of patients receiving fractionated radiotherapy developed new-onset hypopituitarism whereas no complications were observed in the treatment arm that underwent SRS. Though no prospective, randomized, controlled trials have directly compared these two forms of radiation treatment, the relative safety and efficacy of SRS compared with traditional radiotherapy have engendered its use in modern clinical practice.

Although recent case series have adhered to a strict definition of endocrinological remission, earlier studies varied widely in their criteria for hormonal cure, and thus a large range of remission rates was observed (0 to 100\%). At present, most groups consider the following conditions sufficient for endocrinological remission: 1) a random GH level $<2 \mathrm{ng} / \mathrm{ml}$, or 2) a GH level $<0.5 \mathrm{ng} / \mathrm{ml}$ following an oral glucose challenge in addition to a normal IGF-I level when corrected for age and sex. Importantly, all measurements must be obtained while the patient is not receiving pituitary suppressive medications. However, Peacey and Shalet ${ }^{43}$ demonstrated that $\mathrm{GH}$ feedback regulation was disrupted following radiation therapy, and therefore the interpretation of $\mathrm{GH}$ levels following radiosurgical procedures can be problematic. Moreover, given the diurnal and pulsatile secretion pattern of $\mathrm{GH}$, it is often difficult to obtain accurate and true levels. On the other hand, IGF-I has a long half-life and stable concentration within the systemic circulation. ${ }^{37}$ Because GH exerts most of its action through IGF-I, many neurosurgeons and endocrinologists have found single IGF-I measurements to faithfully represent GH activity. In fact, of the studies in our analysis in which a normal IGF-I level was the only criterion for hor- 
monal cure, the rates of endocrinological remission ranged from $20 \%$ to $71 \% .{ }^{18,20,36,48,60}$ As hormonal remission rates following radiosurgery were noted in $17 \%$ to $82 \%$ of patients in studies in which the more stringent criteria were applied, $2,4,5,14,16,21,33,45-47,53,54,57,58$ it appears that the definition of endocrinological remission is of variable consequence.

More important in the postradiosurgical assessment of the patient with acromegaly is the overall length of follow-up. Both Jezková et al. ${ }^{21}$ and Jagannathan et al. ${ }^{18}$ observed remission rates less than $30 \%$ when patients were evaluated 24 months after SRS. However, these rates rose to more than $50 \%$ when follow-up was performed for more than 85 months. In addition, Vik-Mo et al. ${ }^{57}$ saw an endocrinological remission rate of $86 \%$ at 120 months compared with a $45 \%$ cure rate at 36 months of followup. As a result, to thoroughly assess the true efficacy of SRS in the management of acromegaly, patients should ideally receive routine endocrinological evaluations extending 84 to 120 months beyond the radiosurgical procedure. Lengthy and detailed follow-up is also necessary to diagnose cases of recurrent acromegaly. Jagannathan et al. ${ }^{18}$ reported on 3 patients who developed recurrent symptoms of GH excess at 36, 56, and 114 months after SRS. Therefore, as the latency between radiosurgery and hormonal cure or recurrence can be quite long, lengthy endocrinological and radiographic follow-up is necessary to determine the ultimate efficacy of SRS in acromegaly.

The use of somatostatin agonists and GH receptor antagonists in the adjuvant treatment of acromegaly is common practice. ${ }^{35,37}$ However, studies by Landolt et al..$^{26}$ and Pollock et al. ${ }^{46,47}$ demonstrated that patients who concomitantly receive pituitary suppressive medications during radiosurgery experience lower rates of endocrinological normalization than those who terminate medical therapy more than 6 weeks prior to and 6 weeks after SRS. Although the precise mechanism governing this phenomenon is unknown, the current belief is that the suppressive medications place the tumor cells in a quiescent state in which their metabolic and proliferative potential is greatly diminished. By inhibiting cell cycling, these medical therapies reduce the sensitivity of somatotroph cells to the effects of ionizing radiation during DNA synthesis. ${ }^{47}$ However, as no large-scale, prospective, randomized controlled trials have evaluated this question, it is difficult to draw definitive conclusions from small observations. In fact, both Iwai et al. ${ }^{16}$ and Castinetti et al. ${ }^{4}$ observed that pituitary suppressive medication use did not correlate with eventual hormonal outcome, and these differences in observation may be due in part to confounding factors present within each series. For instance, when the concurrent use of pituitary suppressive therapies during radiosurgery is not randomized, patients who require medical therapy for hormonal or symptomatic control are less likely to terminate the medication for a protracted period while those with nearnormal endocrine levels or milder symptoms will better tolerate the hiatus in treatment. Therefore, the difference in remission rates observed by Landolt et al. and Pollock et al. may simply reflect a more aggressive and extensive disease phenotype rather than a true effect of medical therapy. Nevertheless, the practice of discontinuing medical therapy during the radiosurgical procedure has gained clinical acceptance, and certain groups have adopted this strategy in light of these data. ${ }^{16}$ Irrespective of this controversy, pituitary suppressive medications are a critical component of the multimodal management algorithm for patients with acromegaly. For patients in whom radiosurgery is not completely curative, additional medical therapy can offer hormonal normalization in roughly $32 \%$ of patients, according to the series in our analysis. $2,5,8,12,16,17,33,39,44,47,48,53,54,58,59$

In addition to rates of hormonal cure of $17 \%$ to $82 \%$ following SRS, the mean rate of tumor growth control was more than $97 \%$ across the patient series (Table 2). Just as several studies demonstrated that endocrinological normalization increases with time, Mokry et al ${ }^{39}$ reported that tumor volumes progressively decline following SRS. Nevertheless, the stabilization or reduction in adenoma size is not significantly associated with hormonal remission. As a result, except in cases in which the adenoma is compressing critical structures, tumor growth control is an unreliable measure of the success of SRS for the treatment of GH-secreting pituitary lesions. In the future, it will be interesting to determine whether an association between adenoma size and hormonal cure becomes significant as series with larger populations and longer follow-up are reported.

Although surgery remains the first-line treatment for $\mathrm{GH}$-secreting adenomas, resection of tumors that invade the parasellar region is fraught with difficulty. ${ }^{28}$ Because numerous important neurovascular structures traverse the cavernous sinus, SRS offers a noninvasive means of accessing this region in a potentially safe manner. However, exposing the cavernous sinus to a high degree of ionizing radiation places the structures found within it at risk for injury. Nevertheless, in our analysis, new-onset cranial neuropathies and carotid artery stenosis were infrequently observed following SRS. Thus, unlike the optic apparatus, which is especially sensitive to radiation dosing, the structures traversing the cavernous sinus appear more resistant to injury. ${ }^{50,56}$ Kobayashi et al. ${ }^{25}$ reported postradiosurgical visual complications in $11 \%$ of the 67 patients with acromegaly in their study, yet new-onset optic neuropathies were only noted in a total of 10 case series in our review of the literature. To minimize damage to the optic apparatus, many groups attempt to limit the dose it receives to $8-10$ Gy. ${ }^{11}$ In addition, inherent in the dose-planning algorithm is an estimation of the distance between the target tissue and the optic structures. While a distance of at least $5 \mathrm{~mm}$ is desired, Petrovich et al. ${ }^{6,44,50}$ demonstrated that distances of 1 to $2 \mathrm{~mm}$ are acceptable with highly conformal radiation profiles. Furthermore, postradiosurgical anterior hormone dysfunction was observed in 26 of the 45 case series in our analysis. The incidence of hypopituitarism ranged from $2 \%$ to $47 \%$ when reported, and the majority of this hypopituitarism was adequately controlled with supplemental medical therapy. Estimating the true incidence of hypopituitarism following radiosurgery, however, is difficult. Because many patients have received prior surgery or conventional radiotherapy, it is likely that new-onset anterior hormone dysregulation results from an accumulation of insults rendered through numerous treatment modalities. ${ }^{50}$ Overall, complications following SRS for the treatment of acromegaly are uncommon, ${ }^{35}$ and this low rate of adverse 


\section{J. Stapleton, C. Y. Liu, and M. H. Weiss}

effects reflects the reliability with which stereotactic radiosurgical procedures can deliver ionizing radiation that is highly conformal to the target tissue.

When evaluating the efficacy and potential limitations of SRS, it is important to consider the duration of endocrinological and radiographic follow-up. Unlike surgery, SRS requires a protracted period of time before normalization of hormone levels is recognized. A similar degree of followup and observation is necessary to gauge the overall safety of radiosurgical procedures. Jagannathan et al..$^{18}$ reported anterior hormone deficiencies in 34\% of their 95 patients with acromegaly following SRS for failed transsphenoidal operations. A detailed analysis of these cases of new-onset hypopituitarism, however, reveals that the incidence was only $5 \%$ at 12 months after radiosurgery and that more than 49 months of follow-up were necessary to identify the 32 individuals with adverse effects. On the whole, despite a range of infrequent adverse effects, SRS is an efficacious component of the multimodal treatment paradigm for acromegaly. Although dose selection and other treatment parameters vary depending on an array of tumor- and patientspecific characteristics, it is our hope that future studies will more clearly define the optimal treatment strategy for acromegaly and identify the cohort of patients who will maximally benefit from SRS.

\section{Conclusions}

The goal of SRS in the management of GH-secreting pituitary lesions is to reduce hormone overproduction and control tumor growth while preserving normal brain tissue and minimizing adverse effects. In this regard, our analysis of the available literature concerning the use of SRS in acromegaly reveals that radiosurgical procedures induce endocrinological remission in $17 \%$ to $82 \%$ of patients and leads to effective tumor growth control in $97 \%$ of cases when data are analyzed across all series. In addition, because SRS is capable of precisely conforming the radiation field to the tumor target, the overall rate of adverse effects is remarkably low among the series in our analysis. Overall, SRS represents a safe and effective treatment option for patients with primary or recurrent acromegaly.

\section{Disclosure}

The authors report no conflict of interest concerning the materials or methods used in this study or the findings specified in this paper.

Author contributions to the study and manuscript preparation include the following. Conception and design: Weiss, Stapleton. Acquisition of data: Stapleton. Analysis and interpretation of data: Stapleton. Drafting the article: Stapleton. Critically revising the article: all authors. Reviewed final version of the manuscript and approved it for submission: all authors.

\section{References}

1. Adler JR Jr, Chang SD, Murphy MJ, Doty J, Geis P, Hancock SL: The CyberKnife: a frameless robotic system for radiosurgery. Stereotact Funct Neurosurg 69:124-128, 1997

2. Attanasio R, Epaminonda P, Motti E, Giugni E, Ventrella L, Cozzi R, et al: Gamma-Knife radiosurgery in acromegaly: a 4-year follow-up study. J Clin Endocrinol Metab 88:31053112,2003

3. Castinetti F, Morange I, Dufour H, Régis J, Brue T: Radio- therapy and radiosurgery in acromegaly. Pituitary 12:3-10, 2009

4. Castinetti F, Nagai M, Morange I, Dufour H, Caron P, Chanson $\mathrm{P}$, et al: Long-term results of stereotactic radiosurgery in secretory pituitary adenomas. J Clin Endocrinol Metab 94: 3400-3407, 2009

5. Castinetti F, Taieb D, Kuhn JM, Chanson P, Tamura M, Jaquet P, et al: Outcome of Gamma Knife radiosurgery in 82 patients with acromegaly: correlation with initial hypersecretion. J Clin Endocrinol Metab 90:4483-4488, 2005

6. Chen JC, Giannotta SL, Yu C, Petrovich Z, Levy M, Apuzzo MLJ: Radiosurgical management of benign cavernous sinus tumors: dose profiles and acute complications. Neurosurgery 48:1022-1030, 2001

7. Cho CB, Park H, Joo WI, Chough CK, Lee KJ, Rha HK: Stereotactic radiosurgery with the CyberKnife for pituitary adenomas. J Korean Neurosurg Soc 45:157-163, 2009

8. Choi JY, Chang JH, Chang JW, Ha Y, Park YG, Chung SS: Radiologic and hormonal response of functioning pituitary adenomas after Gamma Knife radiosurgery. Yonsei Med J 44:602-607, 2003

9. Feigl GC, Bonelli CN, Berghold A, Mokry M: Effects of Gamma Knife radiosurgery of pituitary adenomas on pituitary function. J Neurosurg 97:415-421, 2002

10. Fukuoka S, Ito T, Takanashi M, Hojo A, Nakamura H: Gamma Knife radiosurgery for growth hormone-secreting pituitary adenomas invading the cavernous sinus. Stereotact Funct Neurosurg 76:213-217, 2001

11. Girkin CA, Comey CH, Lunsford LD, Goodman ML, Kline LB: Radiation optic neuropathy after stereotactic radiosurgery. Ophthalmology 104:1634-1643, 1997

12. Hayashi M, Chernov M, Tamura N, Nagai M, Yomo S, Ochiai $\mathrm{T}$, et al: Gamma Knife robotic microradiosurgery of pituitary adenomas invading the cavernous sinus: treatment concept and results in 89 cases. J Neurooncol 98: 185-194, 2010

13. Hayashi M, Izawa M, Hiyama H, Nakamura S, Atsuchi S, Sato $\mathrm{H}$, et al: Gamma Knife radiosurgery for pituitary adenomas. Stereotact Funct Neurosurg 72:111-118, 1999

14. Ikeda H, Jokura H, Yoshimoto T: Transsphenoidal surgery and adjuvant Gamma Knife treatment for growth hormone-secreting pituitary adenoma. J Neurosurg 95:285-291, 2001

15. Inoue HK, Kohga H, Hirato M, Sasaki T, Ishihara J, Shibazaki $\mathrm{T}$, et al: Pituitary adenomas treated by microsurgery with or without Gamma Knife surgery: experience in 122 cases. Stereotact Funct Neurosurg 72:125-131, 1999

16. Iwai Y, Yamanaka K, Yoshimura M, Kawasaki I, Yamagami K, Yoshioka K: Gamma Knife radiosurgery for growth hormoneproducing adenomas. J Clin Neurosci 17:299-304, 2010

17. Izawa M, Hayashi M, Nakaya K, Satoh H, Ochiai T, Hori T, et al: Gamma Knife radiosurgery for pituitary adenomas. J Neurosurg 93:19-22, 2000

18. Jagannathan J, Sheehan JP, Pouratian N, Laws ER Jr, Steiner L, Vance ML: Gamma Knife radiosurgery for acromegaly: outcomes after failed transsphenoidal surgery. Neurosurgery 62:1262-1270, 2008

19. Jagannathan J, Yen CP, Pouratian N, Laws ER Jr, Sheehan JP: Stereotactic radiosurgery for pituitary adenomas: a comprehensive review of indications, techniques and long-term results using the Gamma Knife. J Neurooncol 92:345-356, 2009

20. Jane JA Jr, Vance ML, Woodburn CJ, Laws ER Jr: Stereotactic radiosurgery for hypersecreting pituitary tumors: part of a multimodality approach. Neurosurg Focus 14(5):e12, 2003

21. Jezková J, Marek J, Hána V, Kršek M, Weiss V, Vladyka V, et al: Gamma Knife radiosurgery for acromegaly-long-term experience. Clin Endocrinol (Oxf) 64:588-595, 2006

22. Kajiwara K, Saito K, Yoshikawa K, Kato S, Akimura T, Nomura $\mathrm{S}$, et al: Image-guided stereotactic radiosurgery with the CyberKnife for pituitary adenomas. Minim Invasive Neurosurg 48:91-96, 2005

23. Kim MS, Lee SI, Sim JH: Gamma Knife radiosurgery for 
functioning pituitary macroadenoma. Stereotact Funct Neurosurg 72:119-124, 1999

24. Kim SH, Huh R, Chang JW, Park YG, Chung SS: Gamma Knife radiosurgery for functioning pituitary adenomas. Stereotact Funct Neurosurg 72:101-110, 1999

25. Kobayashi T, Mori Y, Uchiyama Y, Kida Y, Fujitani S: Longterm results of Gamma Knife surgery for growth hormoneproducing pituitary adenoma: is the disease difficult to cure? J Neurosurg 102:119-123, 2005

26. Landolt AM, Haller D, Lomax N, Scheib S, Schubiger O, Siegfried J, et al: Octreotide may act as a radioprotective agent in acromegaly. J Clin Endocrinol Metab 85:1287-1289, 2000

27. Landolt AM, Haller D, Lomax N, Scheib S, Schubiger O, Siegfried J, et al: Stereotactic radiosurgery for recurrent surgically treated acromegaly: comparison with fractionated radiotherapy. J Neurosurg 88:1002-1008, 1998

28. Laws ER Jr: Surgery for acromegaly: evolution of the techniques and outcomes. Rev Endocr Metab Disord 9:67-70, 2008

29. Laws ER Jr, Sheehan JP, Sheehan JM, Jagannathan J, Jane JA Jr, Oskouian R: Stereotactic radiosurgery for pituitary adenomas: a review of the literature. J Neurooncol 69:257-272, 2004

30. Laws ER Jr, Vance ML: Radiosurgery for pituitary tumors and craniopharyngiomas. Neurosurg Clin N Am 10:327-336, 1999

31. Laws ER Jr, Vance ML, Thapar K: Pituitary surgery for the management of acromegaly. Horm Res 53:71-75, 2000

32. Lim YL, Leem W, Kim TS, Rhee BA, Kim GK: Four years' experiences in the treatment of pituitary adenomas with Gamma Knife radiosurgery. Stereotact Funct Neurosurg 70 Suppl 1:95-109, 1998

33. Losa M, Gioia L, Picozzi P, Franzin A, Valle M, Giovanelli $\mathrm{M}$, et al: The role of stereotactic radiotherapy in patients with growth hormone-secreting pituitary adenomas. J Clin Endocrinol Metab 93:2546-2552, 2008

34. Ludecke DK, Abe T: Transsphenoidal microsurgery for newly diagnosed acromegaly: a personal view after more than 1,000 operations. Neuroendocrinology 83:230-239, 2006

35. Mahmoud-Ahmed AS, Suh JS, Mayberg MR: Gamma Knife radiosurgery in the management of patients with acromegaly: a review. Pituitary 4:223-230, 2001

36. Martínez R, Bravo G, Burzaco J, Rey G: Pituitary tumors and Gamma Knife surgery. Stereotact Funct Neurosurg 70:110 118,1998

37. Melmed S: Medical progress: acromegaly. N Engl J Med 355: 2558-2573, 2006

38. Mitsumori M, Shrieve DC, Alexander E III, Kaiser UB, Richardson GE, Black PM, et al: Initial clinical results of LINACbased stereotactic radiosurgery and stereotactic radiotherapy for pituitary adenomas. Int J Radiat Oncol Biol Phys 42: 573-580, 1998

39. Mokry M, Ramschak-Schwarzer S, Simbrunner J, Ganz JC, Pendl G: A six year experience with the postoperative radiosurgical management of pituitary adenomas. Stereotact Funct Neurosurg 72:88-100, 1999

40. Morange-Ramos I, Régis J, Dufour H, Andrieu JM, Grisoli F, Jaquet P, et al: Short-term endocrinological results after Gamma Knife surgery of pituitary adenomas. Stereotact Funct Neurosurg 70:127-138, 1998

41. Pan L, Zhang E, Wang B, Xu W: Pituitary adenomas: the effect of Gamma Knife radiosurgery on tumor growth and endocrinopathies. Stereotact Funct Neurosurg 70:119-126, 1998

42. Park YG, Chang JW, Kim EY, Chung SS: Gamma Knife surgery in pituitary microadenomas. Yonsei Med J 37:165-173, 1996

43. Peacey SR, Shalet SM: Insulin-like growth factor 1 measurement in diagnosis and management of acromegaly. Ann Clin Biochem 38:297-303, 2001

44. Petrovich Z, Yu C, Giannotta SL, Zee CS, Apuzzo MLJ: Gamma Knife radiosurgery for pituitary adenoma: early results. Neurosurgery 53:51-61, 2003

45. Pollock BE, Brown PD, Nippoldt TB, Young WF Jr: Pituitary tumor type affects the chance of biochemical remission after radiosurgery of hormone-secreting pituitary adenomas. Neurosurgery 62:1271-1278, 2008

46. Pollock BE, Jacob JT, Brown PD, Nippoldt TB: Radiosurgery of growth hormone-producing pituitary adenomas: factors associated with biochemical remission. J Neurosurg 106:833838,2007

47. Pollock BE, Nippoldt TB, Stafford SL, Foote RL, Abboud CF: Results of stereotactic radiosurgery in patients with hormoneproducing pituitary adenomas: factors associated with endocrine normalization. J Neurosurg 97:525-530, 2002

48. Roberts BK, Ouyang DL, Lad SP, Chang SD, Harsh GR IV, Adler JR Jr, et al: Efficacy and safety of CyberKnife radiosurgery for acromegaly. Pituitary 10:19-25, 2007

49. Sanno N, Teramoto A, Osamura RY, Horvath E, Kovacs K, Lloyd RV, et al: Pathology of pituitary tumors. Neurosurg Clin N Am 14:25-39, 2003

50. Sheehan JP, Niranjan A, Sheehan JM, Jane JA Jr, Laws ER Jr, Kondziolka D, et al: Stereotactic radiosurgery for pituitary adenomas: an intermediate review of its safety, efficacy, and role in the neurosurgical treatment armamentarium. J Neurosurg 102:678-691, 2005

51. Shih HA, Loeffler JS: Radiation therapy in acromegaly. Rev Endocr Metab Disord 9:59-65, 2008

52. Shin M, Kurita H, Sasaki T, Tago M, Morita A, Ueki K, et al: Stereotactic radiosurgery for pituitary adenoma invading the cavernous sinus. J Neurosurg 93:2-5, 2000

53. Swords FM, Allan CA, Plowman PN, Sibtain A, Evanson J, Chew SL, et al: Stereotactic radiosurgery XVI: a treatment for previously irradiated pituitary adenomas. J Clin Endocrinol Metab 88:5334-5340, 2003

54. Swords FM, Monson JP, Besser GM, Chew SL, Drake WM, Grossman AB, et al: Gamma Knife radiosurgery: a safe and effective salvage treatment for pituitary tumours not controlled despite conventional radiotherapy. Eur J Endocrinol 161:819-828, 2009

55. Tinnel BA, Henderson MA, Witt TC, Fakiris AJ, Worth RM, Des Rosiers PM, et al: Endocrine response after Gamma Knife-based stereotactic radiosurgery for secretory pituitary adenoma. Stereotact Funct Neurosurg 86:292-296, 2008

56. Tishler RB, Loeffler JS, Lunsford LD, Duma C, Alexander E III, Kooy HM, et al: Tolerance of cranial nerves of the cavernous sinus to radiosurgery. Int J Radiat Oncol Biol Phys 27: 215-221, 1993

57. Vik-Mo EO, Øksnes M, Pedersen PH, Wentzel-Larsen T, Rødahl E, Thorsen F, et al: Gamma Knife stereotactic radiosurgery for acromegaly. Eur J Endocrinol 157:255-263, 2007

58. Voges J, Kocher M, Runge M, Poggenborg J, Lehrke R, Lenartz $\mathrm{D}$, et al: Linear accelerator radiosurgery for pituitary macroadenomas: a 7-year follow-up study. Cancer 107:1355-1364, 2006

59. Wan H, Chihiro O, Yuan S: MASEP gamma knife radiosurgery for secretory pituitary adenomas: experience in 347 cases. J Exp Clin Cancer Res 28:36, 2009

60. Witt TC, Kondziolka D, Flickinger JC, Lunsford LD: Gamma Knife radiosurgery for pituitary tumors, in Lunsford LD, Kondziolka D, Flickinger JC (eds): Gamma Knife Brain Surgery: Progress in Neurological Surgery. Basel: Karger, 1998, Vol 14, pp 114-127

61. Yoon SC, Suh TS, Jang HS, Chung SM, Kim YS, Ryu MR, et al: Clinical results of 24 pituitary macroadenomas with LINAC-based stereotactic radiosurgery. Int J Radiat Oncol Biol Phys 41:849-853, 1998

62. Zhang N, Pan L, Dai J, Wang B, Wang E, Zhang W, et al: Gamma Knife radiosurgery as a primary surgical treatment for hypersecreting pituitary adenomas. Stereotact Funct Neurosurg 75:123-128, 2000

\footnotetext{
Manuscript submitted June 14, 2010.
}

Accepted July 14, 2010.

Address correspondence to: Martin H. Weiss, M.D., Department of Neurological Surgery, Keck School of Medicine, University of Southern California, 1200 North State Street, Suite 3300, Los Angeles, California 90033.email: weiss@usc.edu. 